\title{
Social Change and Increasing of Bipolar Disorders: An Evolutionary Model
}

\author{
Mauro Giovanni Carta*
}

Dipartimento di Sanità Pubblica, Medicina Clinica e Molecolare, Università di Cagliari, Italy

\begin{abstract}
Introduction: The objective of this paper is to see if behaviours defined as pathological and maladjusted in certain contexts may produce adaptive effects in other contexts, especially if they occur in attenuated form. Interactions between environment and behaviour are studied from an evolutionary standpoint in an attempt to understand how new attitudes emerge in an evolving context.

Methodology: Narrative review. Following an historical examination of how the description of depression in Western society has changed, we examine a series of studies performed in areas where great changes have taken place as well as research on emigration from Sardinia in the 1960s and 70s and immigration to Sardinia in the 1990s.

Results and conclusions: If we postulate that mood disorders are on the increase and that the epidemic began in the 17th century with the "English malady", we must suppose that at least the "light" forms have an adaptive advantage, otherwise the expansion of the disorder would have been self-limiting. "Compulsive hyper-responsabilization", as well as explorative behaviours, may represent a base for adaptation in certain conditions of social change. The social emphasis in individualism and responsibility may have changed not only the frequency, but also the phenomenology of mood disorders particularly the increases in bipolar disorders. From the sociobiological standpoint the conditions that may favour "subthreshold" bipolar or depressive features are to be considered in relation to the contextual role of gender and the different risks of the two disorders in males and females.
\end{abstract}

Keywords: Bipolar Disorders, Social Change, Evolutionary Model, Transcultural Psychiatry, Migration.

\section{INTRODUCTION}

This paper is the report on and balance of some thirty years of transcultural research on mood disorders.

The aim of our work was to produce a hypothesis bringing together the different ways in which discomfort manifests itself, with special emphasis on discomfort viewed through mood symptoms.

Our goal was to see if behaviours defined as pathological and which produced maladjustment in the patient in determined contexts may produce adaptive effects in different contexts and, thanks to attenuated expressions, find in these circumstances the conditions for replication and thus become factors leading to social change.

We searched for an interpretation of interactions between environment and behaviours, not from a simplistic perspective that interprets the modalities through which discomfort is expressed as the product of a culture, but by applying an evolutionary approach to see if certain behaviour patterns can be selected from the changing context (since a static context would not modify the social significance of such patterns) and finally to see if the very same behaviours can contribute to influencing the environment.

*Address correspondence to this author at the Dipartimento di Sanità Pubblica, Medicina Clinica e Molecolare, Università di Cagliari, Italy; Tel: +39 3335 499994; Fax: +39 070 6093498; E-mail: mgcarta@tiscali.it
In the case of mood disorders, this amounts to seeing how specific milieus can be adaptive for persons with temperaments or "subthreshold" depressive and/or expansive hyperergic symptoms.

\section{THE ENGLISH MALADY}

Our investigation started from H. B. Murphy's hypothesis [1]. In the 1970s he performed an historical analysis of the descriptions of depression found in Europe, collecting mostly the contributions of physicians and members of the clergy over a period of some centuries. According to Murphy, the symptomatology characterized by low self-esteem, feelings of guilt and helplessness supposedly arose "epidemically" in a specific area of 17th-century England. The phenomenon was already known at the time and was defined as the "English malady". Prior to that time the (rare) descriptions of depression had concentrated on a psychosomatic symptomatology and in particular on symptoms of tiredness and loss of hope.

The changes in symptoms coincided with a period of profound social upheaval: the geographical area was that in which the first historical form of industrialization was taking place in textile manufacturing.

The social change supposedly took place on two interacting levels. Firstly, the rhythms of industrial work marked the end of the extended family typical of the rural world. This was followed by the loss of the close identification of indi- 
viduals with their group or family and the impossibility of maintaining the close emotive relationship that the extended family could provide. The emphasis of the new society on individual responsibility was to represent the other decisive element. The emergence of middle class morals was accompanied by the conviction that individuals were the forgers of their own destinies. The understanding that people were able to manage and guide events emerged among the philosophers in that crucible of middle class culture that was Renaissance Florence (cf. Machiavelli il Principe, reprint 2006 [2]; Pico della Mirandola, Oratio de Hominis Dignitate, in Cassirer 1974[3]) but it developed as "common sense" only in the industrial areas of England in the 17th century. This new interpretation of reality, this new way of perceiving the world and one's active and important role led the development of the middle class concept of moral responsibility. This prospect negated the idea that Providence was the cause and driving force of events and saw individuals as the prime arbiters of their own destinies. Since the reaching of one's goals was to be considered the result of individual efforts, consequently defeats and failures were the result of an individual's ineptitude. Divine indulgence, according to the new Protestant ethic, which took hold with the changing economy, was the reward for the hard work of the good Christian [1].

\section{STUDIES ON DEPRESSION IN AFRICA}

Many studies were carried out in the 1950s and 60s on depression in areas of sub-Saharan Africa in which cultural contacts with Western societies had been limited [4,5]. Thus in this context depression could not be considered a "western" disorder. According to Henry Collomb [6], who had transformed the Fann psychiatric hospital in Dakar into a sort of therapeutic village, depression was to be considered the most significant element in African psychopathology, although clinically the disorder was characterized by ideas of reference, persecutory delusions and psychosomatic symptoms. The ideas of guilt, self-depreciation and suicidal behaviours contrasted with "western" depressive symptomatology [7].

An element of extreme interest in this scenario was reported by Field, who documented an epidemic of a depression-like disorder in an area of Ghana inhabited by Ashanti people [8]. The women were convinced they could recover only after accusing themselves of witchcraft. Murphy [9] interpreted the innovation as a sort of hybrid pathological manifestation combining the traditional psychosomatic discomfort and the innovative pathology apparently introduced by economic individualism represented by the emergence of guilt symptoms, although this was in a context in which these elements were not yet ascribable to a presumed individual conscience as opposed to a more "collective" one related to the concomitant social transformation and the beginning of cacao production on an industrial scale.

The hypothesis advanced by the school of Dakar was that the specificity of Western Africa in expressing discomfort depended on how the main mother-child and communityindividual relationships brought about a sort of symbiotic personality [8]. From this standpoint, the characteristics of the personality were considered to be directly correlated to the way of expressing discomfort, that is, feeling bad and being sad was tantamount to feeling split up, separated from the group the person belonged to and thus threatened and persecuted.

The psychodynamic authors of the 1960s attributed the cause of this particular African depressive pathology to the absence of an individual super-ego: the constant presence of caregiving figures may have determined the development of a collective super-ego $[9,10]$. Later, the sociologist Zempleni-Rabain pointed out that the education of children in Western Africa emphasized the sense of belonging [11]. More recently, thanks to cooperation between the Regional Centre of Traditional Medicine of Bandiagara and the University of Berkeley, the extensive relationship between mother and child was studied by means of aetiological models derived from the "strange situation" in a Dogon village in Mali [12].

\section{COMMUNITY PERSONALITY AND PSYCHOPA- THOLOGY IN SENEGALESE MIGRATION}

A study performed by the school of Dakar [13] observed that Senegalese emigrants who had moved to Dakar from rural areas were found to be protected from the psychopathological risk connected with migration by the effect of social cohesion thanks to the associative structures of the Islamic brotherhoods. These institutions were thought to represent the social manifestation of the community's attitude towards personality in a syncretic Islamism still imbued with magic and religious elements.

Sylla and Mbaye studied the modalities by which these networks modulated the need for group unity, the necessity to emigrate and psychological risk among Western African populations, especially the Wolofs of Senegal [14]. The departure to seek work is preceded by magic rituals known as "Narval" in the Wolof language. The social significance of the ritual is that of creating a bond that places the individual under the control of the mother or wife in the mother country. Since the family depends on the remittances that the emigrant sends from abroad, it is fundamental to have a ritual that modulates the effects of an experience that risks being strongly centrifugal with respect to the community. It is believed that the emigrant can be recalled thanks to a ceremony called Wotal; if he does not respond he will lose his mental health. Thanks to this bond the family can be sure of receiving periodic remittances from the family member abroad: distance does not break the bond with the group to which the emigrant belongs. Offers in money to the brotherhood also exonerate the emigrant from the obligation to remain at home. According to the Koran, emigration to places where the true faith is not practised is allowed only for religious reasons.

Almost all Senegalese emigrants with psychotic disorders observed starting from the 1990s in our centre were convinced that they were influenced by the Wotal. The clinical pictures were characterized by bouffées with persecutorylike delusions and mental confusion.

The onset of an episode was perceived as a breaking of the symbiotic bond with the group. It is thus not therapeutically surprising that on the return to Senegal of a relative 
with a psychotic maladjustment a series of traditional rituals are performed by family and friends to remove the negative effects of the Wotal [14].

In a study performed in Sardinia $[15,16]$, a random sample of Senegalese street traders, whose work made community life possible, did not appear to be at risk of depression any more than Sardinian controls. Unexpectedly, a high frequency of anxiety and depressive disorders was found in the few Senegalese who had found regular jobs and pay. A strong determinant associated with the onset of the psychopathology was, in this second case, the loss of contact with their fellow Senegalese and the breaking away from the brotherhood. Compared to a population of Moroccan emigrants employed in similar jobs, the Senegalese street traders presented a lower risk of depression as well as a lower incidence of psychopathological episodes in the first months after their arrival in Sardinia. This is probably connected to a more active role of social support [15].

\section{THE BANDIAGARA STUDY IN MALI}

The observations on African emigrants encouraged our group to perform a series of in-the-field studies in Africa.

The first project was on the Bandiagara plateau in Mali. This is where a research centre funded by Italian Cooperation for Development and the Centre Régional de Médicine Traditionnelle was set up. The cooperative project proposed to use the principles of Dogon herbal medicines to produce low-cost drugs [17]. The method of testing the efficacy and standardizing the active ingredients was introduced based on the traditional empirical grounds of Western scientific culture. From this standpoint, a study conducted together with local medicine men was indispensable to compare traditional nosography with Western disease classifications. It was necessary to understand which active ingredients could be useful and for which disease [17]. It emerged that depressive and anxiety disorders were unknown and not taken into consideration by the medicine men [18]. On the plateau they either did not exist or were not considered as falling within the scope of the system of treatment. This is the background of the investigation that we performed at Bandiagara. Laboriously, and with the help of many linguists, we translated some of the epidemiological instruments used in Europe in epidemiological investigations of mental health. We then performed a study to verify the presence of depression on the Dogon plateau. It was a study conducted using western nosological criteria but with the intention of comparing them to the interpretive modalities of the culture under examination, studied according to the approach that anthropologists and new transcultural psychiatrists would define as dialectic between "etic" and "emic" [19,20].

The population studied lived in a very poor Sahelian area in nomadic camps (the Peuls) or villages (the Dogons) with no electricity, organized transport or communications systems [21]. Almost the entire cohort was illiterate. Thus we are dealing with a study of extreme interest owing to its singularity, albeit next to impossible to replicate. Numerous observations in Western Africa appear, in faft, to indicate a progressive change, today, in psychopathology, especially in circles that are urban and literate in the western sense [22, 23].
The prevalence of depressive disorders found the Dogon plateau was lower than what have found in studies performed in Europe with similar instruments or in Africa in urban contexts or in conditions of war [24, 25]. Among the illiterates, who were a consistent part of the cohort, most depressed individuals also suffered from somatic disorders that had begun prior to the onset of the psychiatric disorder. The study showed the importance of somatic diseases as a risk factor for depression when the reproductive role (as in the case of parasitic infections of the genitourinary tract) or the social or family role (as in the case of heart diseases and tuberculosis) have been affected [21].

Thus, in the societies studied, we may find a behavioural pattern similar, but not identical, to our depressive patterns. But this is rare, probably because its onset requires a triggering condition of higher impact. Moreover, in agreement with what has been demonstrated by other studies, depression is not considered a disease and thus does not fall within conventional or traditional treatment systems.

A later work [26] aimed at characterizing the syndromic aggregations by means of a sophisticated statistical method based on how a symptom is more likely to occur associated with one or more symptoms. The results suggest a nonsuperimposition of the depressive phenomenology most frequently found on the Dogon plateau on the psychological profiles usually found in western contexts. It also appears to confirm the existence of two opposing ways of expressing the discomfort which are most likely "culturally determined" [27]. One way is more frequent and characterized by psychoastenic symptoms with persecutory overtones, while the other, similar to depression as we in industrialized countries know it, is found in literate persons.

\section{THE NAMWERA STUDY IN MALAWI}

The Bandiagara study suggests that social factors influence the manifestation of the melancholy phenomenology and perhaps they may affect the risk of becoming depressed, but it does not allow us to formulate any hypothesis explaining how this may come about.

Some elements of interest on this subject are presented in the results of an investigation carried out in the Namwera area in Malawi, bordering on Mozambique [28]. In this region, inhabited by Yao and Chicewa peoples, the economy was prevalently based on farming and only at the time of the study had other occupations emerged. Malawi was in fact the only African country that had maintained a strongly traditional political structure up to the 1990s; urbanization had been opposed by the central government, which had officially acknowledged the village chief as its representative [28].

Malawi is in southwest Africa. It is one of the poorest countries in the world with the highest rate of HIV infections. However, at the time of the study, Malawi had undergone profound transformations involving micro- and macrosocial aspects and which, in the following years, had led to the setting up of a democracy with different political parties determined by a referendum. In a world that had not changed for centuries, these changes had a strong emotive impact on most of the population. In the period just before the referen- 
dum, McLachlan had observed and described an authentic epidemic of forms of hysteria in groups of young women [29]. According to the only western psychopathologist present, these phenomena were to be considered directly related to the hyper-involvement caused by conflict in the choice between tradition and innovation. The hysterical crises invariably began with triggering events brought on by occurrences connected with the referendum, such as political rallies and public debates [29].

In this context, starting from 1988, an industrial apparel initiative planned and financed by Italian cooperation had been set up in the village of Namwera. At the beginning, the project foresaw that after a training period women could purchase the machines required for setting up an independent dressmaking activity in their villages of origin. In consideration of the peculiar condition of women in the Yao and Chicewa cultures, the sudden passage from a traditional role to one that was to some extent entrepreneurial appeared to be a situation appropriate for studying aspects concerning the relationship between transformation of the self and psychopathological modifications.

The investigation concerned three cohorts of women matched by age: one included all the dressmakers, another with women employed in traditional occupations (farmers/housewives) and the third with nurses and midwives.

The history of development, the presence of stressful events and other risk factors, such as the presence of psychopathological symptoms and evident psychiatric disorders, were studied; interpretations of the causes of any discomfort found were defined.

The choice of the kind of non-traditional work made by the young women was in line with their personal histories of development. In fact, those who were employed in innovative jobs (dressmakers and nurses) had suffered abandonment by the father at an early age (in more than $80 \%$ of the two cohorts). In Malawi, marriage is matrilocal: the man moves to his wife's home, but he often abandons the family, leaving it in precarious economic conditions. In the young dressmakers and nurses the choice of an innovative occupation was probably dictated by economic needs and subsistence. Satisfaction with their work was higher in the women who had chosen innovative occupations (dressmakers and nurses) but only the dressmakers (and not the nurses) manifested a series of social conflicts connected with their new roles, such as difficulty in finding a stable partner and frequent abandonment by husbands who refused to accept the wife's work, and this is surprising in consideration of the economic stability that the new activity offered. On the level of psychopathological evaluation, the housewives and dressmakers more often appeared distressed than did the nurses. They presented more psychopathological symptoms and, among these, the number of cases of depression diagnosed on the basis of the DSM-IIIR manual was higher.

Among the housewives, a statistical analysis of the distribution of the specific symptoms revealed more frequent "psychosomatic" symptoms (headaches, lack of appetite, poor digestion), excessive tiredness, loss of interest and difficulty in concentrating, ideas of devaluation, conviction that others did not acknowledge the importance of their roles and that an insult by someone may have caused the problems. They thus showed a tendency to suffer from a lack of respect by others and to localize externally the causes of their malaise. The dressmakers more often felt tense, nervous and worried; they experienced sensations of uselessness and more frequently expressed a wish to die. More than in the control groups, problems involving self-esteem and the more conventional symptoms of depression emerged. The nurses were found to enjoy a higher level of psychological wellbeing.

Some interesting psychosocial studies suggest that cultural transmission tends to remain when the specific cultural institutions (in the case of the Namwera study the occupational role) are perceived by the persons involved (and by the other members of the group) as an integral part of their own personal identity, but at the same time as capable of responding to new exigencies and needs ("the evolving self") [30].

In the case of the Namwera study this interpretation would explain the absence of external and internal conflicts connected with the new role and, consequently, the nurses' in integrating into it. They receive a good salary but maintain a social role similar to that of the female tradition.

On the contrary, the dressmakers, who were involved in a more individualistic occupation that was farther removed from women's traditional role, appeared to suffer more from the burden of an activity completely different in terms of individual responsibility and one that was probably less acceptable in the social and family context.

In interpreting the results we must take into consideration that a nurse's work appears to allow a Namwera woman to maintain an acceptable social role, one that is also perceived as being closer to women's "traditional" roles, especially as concerns care for and support of the weak. Thus it is not surprising that nurses form the emotionally most stable group, since they have reached a satisfactory economic situation which provides them with independence and autonomy, while maintaining them in an individually and socially acceptable role which is also innovative.

We can also hypothesize that extreme needs, such as those caused by abandonment by a father, can cause inclined individuals to assume the onus of the problems of the microgroup and take a "step forward" (new occupation or emigration). The choice of the new activity brings with it the risk of a breakaway from tradition if not adequately mediated. The cultural change would thus offer opportunities for success of individuals who are "desperate, explorative and superresponsible" (with "compulsive hyper-responsibilization" in Bowlbian terms) [31] while in other circumstances "unperturbed" by the change, they would probably be destined to undergo social humiliation. The social change from an evolutionary standpoint may also form the substrate that favours, selects and amplifies the frequency of behaviour of this kind. At the same time, this exposes to decompensation: the step may be rewarded, but those who take it are more at risk: they are alone on a new road and do not have the support of the group, which no longer recognizes them and tends to isolate them. The model may explain not only the transformation of the symptoms (centred on responsibility 
and guilt) but also the supposed increase in depression in western society.

\section{IS DEPRESSION ON THE INCREASE IN WESTERN SOCIETY?}

The supposed increase in depression in western societies cannot in fact be explained by "ingenuous" biological and genetic hypotheses: it is irrational if not interpreted from a complex socio-biological standpoint. If depression were simply caused by genetic vulnerability we could not explain why a condition that afflicts persons who live shorter lives and give birth to fewer children does not disappear, but according to some has seen a continuous increase from the 17 th century to the present.

The fact that depression is actually on the increase is debatable. Some studies appear to demonstrate it: the Swedish study repeated over time by Lundby [32]; the analysis of data of the national study in the United States conducted in the 1980s which, however, is a cross-sectional study [33]; a study at the general practitioner level in the United Kingdom covering about thirty years [34].

However, there are studies that do not appear to confirm this trend, such as the well-known study repeated over time in Stirling County, Nova Scotia $[35,36]$.

More recently, the two studies performed on a population sample in the United States (of what first evaluation in 1992 and repeated in 2002) [37], and the Australian study in New South Wales (first evaluation in 1998 and repeated in 2008) [38], appear undoubtedly to confirm the hypothesis of an increase in the prevalence and incidence of depression at least in the last few decades.

\section{THE DECREASE IN DEPRESSION IN SARDINIA'S MINING DISTRICT: IS IT THE RESULT OF SELEC- TIVE MIGRATION?}

Sardinians, apparently, go in the opposite direction: this emerges from the data of our latest study performed in a Sardinian mining district with three estimates of the frequency of depression in the overall population in 1988, 1998 and 2008 [39]. The pervasiveness of depression clearly appears to be decreasing in the last twenty years and, at least in the last ten years, the comparison with the first investigation needs to be considered with more caution in the light of the different interviewing method used and the fact that the diagnostic system had changed. In the ten years preceding the first study the area had seen a $50 \%$ decrease in the population in forty years. We have asked ourselves whether this decrease against the general trend has been caused by selective migration, that is, the departure of persons who were in some way "vulnerable" to depression.

A certain popular literature has underscored that migration may select persons with "hypomanic temperaments". Gartner, in his book "The Link between (a little) Craziness and (a lot of) Success in America" [40] advances the hypothesis that success in America is due to immigrants who are more ambitious, determined, creative and resistant to frustration than others. The author, a psychiatrist well-known to the media, argues that emigrants are more frequently persons with hypomanic traits. This is an apparently "naive" theory, but one that may confirm what we stated as concerns the results in the mining district. We must in fact consider that persons with a hypo-manic temperament are more exposed than others to depressive episodes.

\section{STUDIES ON SARDINIAN EMIGRATION}

I defined Gartner's theory as naive because we cannot argue that all emigrants leave for similar reasons and with the same determination to accept a challenge. It is sufficient to consider refugees who are forced to abandon their homes rather than choosing to leave them.

To arrive at a better understanding of the dynamics of possible selective, we attempted to study the specificity of Sardinian emigration.

In the 1960s, Nereide Rudas studied attitudes towards migration in Sardinian couples who were about to leave for Germany, France and Northern Italy [41, 42]. The decision to emigrate was mostly made by the husbands. The wives often did not agree completely, but bowed to the will of their spouses. Although in our culture women have a voice in decision-making within the family, generally speaking they are more respectful of traditions and probably for this reason they were less enthusiastic about leaving. On the average, the migrating women had less self-esteem than the men [43].

A long time after the first study we performed research on Sardinian immigrants in Paris at the beginning of the 1990s [44]. Most of these persons came from the northern Ogliastra and Barbagia regions; they had left in the 1960s and 70s from sheep raising areas of those regions which were poor and at that time with few prospects for the future. The study compared the frequency of psychopathological disorders in a cohort of Sardinians residing in Sardinia, in a cohort of Sardinians residing in Paris and in a cohort of Parisians. The Sardinians in Sardinia were found to be more frequently anxious and the Parisians more often depressed. The emigrants were in the worst condition: they were as anxious as the Sardinians who had remained at home and there were more cases of depression; the young males were those most prone to depression. The depressive symptoms, especially among the young males, were frequently associated with substance abuse and anxiety disorders and more often chronic compared to depressed Parisians.

The passage from a static society with few opportunities to one with many opportunities, but highly competitive, appeared to increase the risk, especially in males, and even more in young males.

A similar study conducted in a completely different situation, that of the economic collapse in Argentina, the investigation had been conducted at La Plata and in the south of the province of Buenos Aires in December 2001 and in 2002, showed that the young male Sardinian immigrants were not the ones at risk [45]. In these specific circumstances those at risk were the women over the age of forty-five, the group traditionally considered the most vulnerable to major depressive disorders.

In conclusion, a condition offering many opportunities, especially for young men who are competitive and full of initiative, appears to place at risk some of the very youths that the condition should favour. This recalls the theory of 
goal striving stress described by Kleiner and Parker [46]: a society that creates great expectations produces stress in those who fail to reach their goals. A society in full economic and social catastrophe represents a risk for adult women emigrants. These were women who had not chosen to emigrate and who, at the time of departure, had less selfconfidence than the men.

\section{CONCLUSIONS}

If we hypothesize that mood disorders are increasing and that the forms of them we know have appeared as mass phenomena at least starting from the 17th century, we must also postulate that at least the "minor" forms must have an adaptive advantage (otherwise the disorder would have disappeared). "Compulsive hyper-responsabilization" may represent an adaptive substrate in certain conditions of social change.

After becoming entrepreneurs, many young Namwera seamstresses improved their economic and social status in the 1990s, just as many Sardinians who today have reached a solid social position in Paris, but who in those years faced a difficult challenge in a world completely different from their traditional one. A certain attitude towards challenges and hyperactivity may have facilitated their choice to make the social change or decide to emigrate. Although social interactions may have caused, such as in the case of the Sardinians pairs, the selection of women rated to pessimism and the sense of duty.

At the same time new opportunities may also appear as risky: those who accept challenges can reach new goals, but are also exposed to a greater risk of defeat compared to those who remain in their traditional roles or do not emigrate. The "new" selected people also expressed their suffering in a new, more "individualistic" way.

The social changes that favour compulsive hyperresponsibilization are those that disrupt the support "extended" to the individual: this social hypothesis comes from Murphy's theories and, in agreement with the results of the Namwera study, it is perfectly in line with researches on human ethology which "anxious avoidant attachment" to a greater exploratory attitude but also to an increased risk of depression [47].

A similar model can explain how the accent on individualism and responsibility has changed not only the frequency, but also the phenomenology of mood disorders.

We have spoken of depression in general terms.

What emerges is the increase in our culture of depression among young men (not only in the Paris investigation, but also in many European, North American and Australian studies [37, 38, 48]); the increase in forms of co-morbidity, especially with substance addiction and anxiety (an element not isolated in our studies) may give weight to the theory of the increase in bipolar disorders. Because, is doubtable that common epidemiologic tools have ability to detect between Bipolar Depressive Episodes and Major Depressive Episodes [49-51].

The sociobiologically determined roles of gender and their interaction may also increase the level of complexity. A couple composed of a hyper-explorative male and a traditionally protective female undoubtedly presents adaptive advantages in particular contexts of tumultuous changes, such as those that occur in an unfamiliar world in a couple of migrants, as has been described in studies on Sardinians.

It is reasonable to expect that different social conditions are capable of triggering specific vulnerabilities in the two sexes and that the interaction between environment and hormonal structure may produce the different psychopathological expression [48].

The socioeconomic context found in Paris in our investigation recalls scenarios common to Europe in the last forty years. The "Argentine model" appears to reflect that of Europe in the next ten years. There will be a new change in the phenomenology of mood disorders in the future?

\section{CONFLICT OF INTEREST}

The authors confirm that this article content has no conflicts of interest.

\section{ACKNOWLEDGEMENT}

Declared none.

\section{REFERENCES}

[1] Murphy HB. The advent of guilt feelings as a common depressive symptom, Psychiatry 1978; 41:229-42.

[2] Machiavelli N. Il Principe, a cura di Giorgio Inglese, con un saggio di Federico Chabod, Einaudi, 2006.

[3] Cassirer E, Individuo e cosmo nella filosofia del Rinascimento (1927), trad. it., La Nuova Italia, Firenze 1974.

[4] Asuni T. Suicide in Western Nigeria. Int J Psychiatry 1965; 1: $52-$ 63.

[5] Weinberg SK. Cultural aspects of manic-depression in West Africa. J Health Hum Behav 1965; 6(4): 247-53.

[6] Collomb H. Les aspects culturels des depressions. Revue du Prat 1978; 28: 3025-31.

[7] Collomb H, Collignon R. Les coduites suicidaires en Afriques. Psychopathol Afr X 1974; 1: 55-113.

[8] Field L. Search of Secutity. Boston: North Western University Press 1960.

[9] Murphy HB. Depression nerveuse croyance a la Sorcellerie et development du surmoi. Psychopathol Afr 1980; 2: 171-94.

[10] Murphy HB, Wittkower ED, Chance NA. Crosscultural inquiry into the symptomatology of depression: a preliminary report. Int $\mathbf{J}$ Psychiatry 1967; 3(1): 6-15.

[11] Zempleni Rabain J. L'enfant du lignage. Du sevrage à la classe d'age chez les Wolof. Paris: Payot 1979.

[12] True MM, Pisani L, Oumar F. Infant-mother attachment among the Dogon of Mali. Child Dev 2001; 72(5): 1451-66.

[13] Diop MC. Le fénomène associatif mouride en ville: expression du dynamisme confrérique. Psychopathol Afr 1982; 3: 293-31.

[14] Sylla O, Mbaye M. Psychopathologie e migration: a propos d'un cas de Wotal. Psychopathol Afr 1991; 3: 353-64.

[15] Carta MG, Carpiniello B, Rudas N. L'èmigration senegalaise et marocaine en Sardaigne. Psychopathol Afr 1991; 3: 329-52.

[16] Carta MG, Coppo P, Reda MA, Hardoy MC, Carpiniello B. Depression and social change. From transcultural psychiatry to a constructivist model. Epidemiol Psichiatr Soc 10: 46-58: 2001.

[17] Coppo P, Keita A. Medicine traditionaille. Acteurs et itineraires terapeutiques. Trieste : Edizioni E, 1990.

[18] Coppo P. Essai de psychopathologie dogon. Perugia : CRTM 1993.

[19] Leff J. The new cross cultural psychiatry. A case of the baby and the bathwater. Br J Psychiatry 1990; 156: 305-7.

[20] Littlewood R. From categories to context: a decade of the new cross cultural psychiatry. Br J Psychiatry 1990; 156: 308-27.

[21] Carta MG, Coppo P, Carpiniello B, Mounkuoro PP. Mental disorders and health care seeking in Bandiagara. A community survey in 
the Dogon plateau. Soc Psychiatry Psychiatr Epidemiol 1997; 32: 222-9.

[22] Bitinie A. The clinical manifestations of depression in Africa. Psychopathol Afr 1981; 17: 36-40.

[23] Colla J, Buka S, Harrington D, Murphy JM. Depression and modernization: a cross-cultural study of women. Soc Psychiatry Psychiatr Epidemiol 2006; 41(4): 271-9.

[24] Abas MA, Broadhead JC. Depression among women in an urban setting in Zimbabwe. Psychol Med 1997; 27: 59-71.

[25] Orley J, Wing JK. Psychiatric disorders in two African villages. Archi Gen Psychiatr 1979; 36, 513-20.

[26] Carta MG, Coppo P, Reda MA, Mounkuoro PP, Carpiniello B. Psychopathology in the Dogon plateau: an assessment using the QDSM and principal components analysis. Soc Psychiatry Psychiatr Epidemiol 1999; 34: 282-5.

[27] Kiev A. Transcultural psychiatry. Free Press: New York 1972.

[28] Carta MG, Carpiniello B, Dazzan P, Reda MA. Depressive symptoms and occupational role among female groups: a research in a south-east african village. Psychopathology 2000; 32, 240-5.

[29] Mac Lachlan M, Maluwa Banda D, McAulifer E. Epidemic disturbances in a malawian secondary school: a case study in social change. Psychol Dev Soc 1995; 7(1): 79-90.

[30] Csikszentmihalyi M. The evolving self. A psychology for the third millennium. New York: Harper Collins 1993.

[31] Bowlby J. Loss, sadness and depression. London: Hogarth 1980.

[32] Hagnell O, Lanke J, Rorsman B, Ojesjö L. Are we entering an age of melancholy? Depressive illnesses in a prospective epidemiological study over 25 years: the Lundby Study, Sweden. Psychol Med 1982; 12(2): 279-89.

[33] Wickramaratne PJ, Weissman MM, Leaf PJ, Holford TR. Age, period and cohort effects on the risk of major depression: results from five United States communities. J Clin Epidemiol 1989; 42(4): 333-43.

[34] Dunn G, Skuse D. The natural history of depression in general practice: stochastic models. Psychol Med 1981; 11(4): 755-64.

[35] Murphy JM, Laird NM, Monson RR, Sobol AM, Leighton AH. A 40-year perspective on the prevalence of depression: the Stirling County Study. Arch Gen Psychiatry 2000; 57(3): 209-15.

[36] Murphy JM, Laird NM, Monson RR, Sobol AM, Leighton AH. Incidence of depression in the Stirling County Study: historical and comparative perspectives. Psychol Med 2000; 30(3): 505-14.

[37] Compton WM, Conway KP, Stinson FS, Grant BF. Changes in the prevalence of major depression and comorbid substance use disorders in the United States between 1991-1992 and 2001-2002. Am J Psychiatry 2006; 163: 2141-7.
[38] Goldney RD, Eckert KA, Hawthorne G, Taylor AW. Changes in the prevalence of major depression in an Australian community sample between 1998 and 2008. Aust N Z J Psychiatry 2010; 44: 901-10.

[39] Carta MG, Mura G, Lecca ME, et al. Decreases in depression over 20years in a mining area of Sardinia: Due to selective migration? J Affect Disord 2012; 141(2-3): 255-60.

[40] Gardner DJ. The Hypomanic Edge: The Link Between (A Little) Craziness and (A Lot of) Success in America. New York, NY, USA: Simon \& Schuster 2005.

[41] Rudas N, L'emigrazione Sarda. Caratteristiche strutturali e dinamiche, "Studi Emigrazione", Conferenza Nazionale dell'Emigrazione, 35, Roma 1974.

[42] Rudas N, Alcuni aspetti di base dell'emigrazione sarda, Studi Emigrazione 34, Roma 1974.

[43] Carta MG, Moro MF, Kovess V, et al. Could Hypomanic Traits Explain Selective Migration? Verifying the Hypothesis by the Surveys on Sardinian Migrants. Clin Pract Epidemiol Ment Health 2012; 8: 175-9.

[44] Carta MG, Kovess V, Hardoy MC, Morosini PL, Murgia S, Carpiniello B. Psychiatric disorders in sardinian immigrants in Paris: a comparison with parisians and sardinians resident in Sardinia. Soc Psychiatry Psychiatr Epidemiol 2002; 37: 112-7.

[45] Carta MG, Reda MA, Consul ME, et al. Depressive episodes in Sardinian emigrants to Argentina: why are females at risk? Soc Psychiatry Psychiatr Epidemiol 2006; 41: 452-6.

[46] Kleiner RI, Parker I. Social psychological aspects of migration. In: Brody ED, Ed. Behaviour in new environments. NY: Sage 1979.

[47] Bifulco A, Moran PM, Ball C, Bernazzani O. Adult attachment style. I: Its relationship to clinical depression. Soc Psychiatry Psychiatr Epidemiol 2002; 37(2): 50-9.

[48] Carta MG, Aguglia E, Bocchetta A, et al. The Use of Antidepressant Drugs and the Lifetime Prevalence of Major Depressive Disorders in Italy. Clin Pract Epidemiol Ment Health 2010; 6: 94-100.

[49] Angst J, Meyer TD, Adolfsson R, et al. Hypomania: a transcultural perspective. World Psychiatry 2010; 9(1): 41-9.

[50] Carta MG, Angst J. Epidemiological and clinical aspects of bipolar disorders: controversies or a common need to redefine the aims and methodological aspects of surveys. Clin Pract Epidemol Ment Health 2005; 1(1): 4.

[51] Carta MG, Balestrieri M, Murru A, Hardoy MC. Adjustment Disorder: epidemiology, diagnosis and treatment. Clin Pract Epidemiol Ment Health 2009; 5:15.

Received: March 29, 2013

Revised: April 13, 2013

Accepted: May 15, 2013

(C) Mauro Giovanni Carta; Licensee Bentham Open.

This is an open access article licensed under the terms of the Creative Commons Attribution Non-Commercial License (http://creativecommons.org/licenses/by-nc/3.0/) which permits unrestricted, non-commercial use, distribution and reproduction in any medium, provided the work is properly cited. 